\title{
Carbohydrate supplementation during prolonged cycling exercise spares muscle glycogen but does not affect intramyocellular lipid use
}

\author{
Trent Stellingwerff $•$ Hanneke Boon • \\ Annemie P. Gijsen • Jos H. C. H. Stegen • \\ Harm Kuipers • Luc J. C. van Loon
}

Received: 25 November 2006 / Revised: 8 January 2007 / Accepted: 12 February 2007 / Published online: 27 February 2007

(C) Springer-Verlag 2007

\begin{abstract}
Using contemporary stable-isotope methodology and fluorescence microscopy, we assessed the impact of carbohydrate supplementation on whole-body and fibertype-specific intramyocellular triacylglycerol (IMTG) and glycogen use during prolonged endurance exercise. Ten endurance-trained male subjects were studied twice during $3 \mathrm{~h}$ of cycling at $63 \pm 4 \%$ of maximal $\mathrm{O}_{2}$ uptake with either glucose ingestion ( $\mathrm{CHO}$ trial; $0.7 \mathrm{~g} \mathrm{CHO} \mathrm{kg}^{-1} \mathrm{~h}^{-1}$ ) or without (CON placebo trial; water only). Continuous infusions with $\left[\mathrm{U}^{-13} \mathrm{C}\right]$ palmitate and $\left[6,6-{ }^{2} \mathrm{H}_{2}\right]$ glucose were applied to quantify plasma free fatty acids (FFA) and glucose oxidation rates and to estimate intramyocellular lipid and glycogen use. Before and after exercise, muscle biopsy samples were taken to quantify fiber-type-specific IMTG and glycogen content. Plasma glucose rate of appearance $\left(R_{\mathrm{a}}\right)$ and carbohydrate oxidation rates were substantially greater in the $\mathrm{CHO}$ vs $\mathrm{CON}$ trial. Carbohydrate supplementation resulted in a lower muscle glycogen use during the first hour of exercise in the $\mathrm{CHO}$ vs $\mathrm{CON}$ trial, resulting in a $38 \pm 19$ and $57 \pm 22 \%$ decreased utilization in type I and II muscle-fiber glycogen content, respectively. In the $\mathrm{CHO}$ trial, both plasma FFA $R_{\mathrm{a}}$ and subsequent plasma FFA concentrations were lower, result-
\end{abstract}

T. Stellingwerff $(\bowtie) \cdot$ H. Kuipers $\cdot$ L. J. C. van Loon

Department of Movement Sciences,

Nutrition Research Institute Maastricht (NUTRIM),

Maastricht University,

P.O. Box 616, 6200 MD Maastricht, The Netherlands

e-mail: trent.stellingwerff@rdls.nestle.com

H. Boon - A. P. Gijsen · J. H. C. H. Stegen · L. J. C. van Loon

Department of Human Biology,

Nutrition Research Institute Maastricht (NUTRIM),

Maastricht University,

Maastricht, The Netherlands ing in a $34 \pm 12 \%$ reduction in plasma FFA oxidation rates during exercise $(P<0.05)$. Carbohydrate intake did not augment IMTG utilization, as fluorescence microscopy revealed a $76 \pm 21$ and $78 \pm 22 \%$ reduction in type I muscle-fiber lipid content in the $\mathrm{CHO}$ and $\mathrm{CON}$ trial, respectively. We conclude that carbohydrate supplementation during prolonged cycling exercise does not modulate IMTG use but spares muscle glycogen use during the initial stages of exercise in endurance-trained men.

Keywords Fat metabolism · Intramyocellular triacylglycerol · IMTG · Glycogen · Sports drinks · Isotopes · Exercise

\section{Introduction}

During exercise, there is a complex interaction between carbohydrate and fat metabolism to provide the required adenosine triphosphate (ATP) to sustain the necessary power output. The relative utilization of endogenous fat and carbohydrate stores during exercise can vary enormously and strongly depends on exercise intensity [28, 38], duration $[28,41,45]$, and training status $[19,36]$. During moderate intensity exercise, the oxidation of plasmaderived free fatty acids (FFA) in conjunction with other fat sources (muscle- and/or lipoprotein-derived triacylglycerol) contributes approximately half of the total energy required for contracting skeletal muscle. As the exercise duration lengthens, there is an increasing contribution of fat oxidation to total energy expenditure, which is primarily attributed to an increase in the release, uptake, and oxidation of plasma FFA [28, 41, 45]. Studies utilizing more prolonged $(\geq 2 \mathrm{~h}$ ) moderate-intensity exercise proto- 
cols have consistently shown that the progressive increase in plasma-FFA delivery to working skeletal muscle late in the exercise coincides with an inhibition of intramyocellular lipid (intramyocellular triacylglycerol [IMTG]) mobilization and/or oxidation [28, 41, 45]. In accordance, pharmacological inhibition of adipose tissue lipolysis has been shown to stimulate the use of intramyocellular lipids during the latter stages of prolonged exercise [42, 44, 47]. Carbohydrate supplementation can also serve to decrease FFA delivery and lower whole-body fat-oxidation rates during exercise $[9,10]$. Therefore, it could be hypothesized that the reduced FFA availability via carbohydrate supplementation stimulates IMTG use during the latter stages of prolonged exercise. In contrast, other studies have reported an inhibitory effect of glucose ingestion on hormonesensitive lipase activity [48], which would actually reduce IMTG hydrolysis [11]. It therefore remains to be established how carbohydrate supplementation during exercise modulates IMTG utilization.

Carbohydrate supplementation during exercise has been reported to improve endurance performance by maintaining euglycemia during the late stages of prolonged exercise and/or by sparing the muscle glycogen stores [9]. However, the latter remains equivocal, as most studies have failed to report muscle glycogen sparing after carbohydrate supplementation during prolonged cycling exercise $[5,9,13,17$, $24,25]$. The inconsistent findings of the effects of carbohydrate supplementation on subsequent muscle glycogen sparing may likely be attributed to differences in the applied research design, with specific reference to the mode of exercise (running vs cycling) and/or specific muscle group and/or fiber type recruitment [33].

The present study applies continuous infusions of $\left[\mathrm{U}_{-}{ }^{13} \mathrm{C}\right]$ palmitate and $\left[6,6-{ }^{2} \mathrm{H}_{2}\right]$ glucose with muscle biopsy sampling before and after exercise to quantify both whole-body and muscle-fiber-type-specific IMTG and glycogen use. The purpose of this study was to assess the impact of carbohydrate supplementation on skeletal muscle glycogen and intramyocellular lipid use during prolonged cycling exercise in endurance-trained men and, as such, to determine whether carbohydrate supplementation reduces muscle glycogen use and/or augments the use of the IMTG pool as a substrate source.

\section{Materials and methods}

\section{Subjects}

Ten endurance-trained male cyclists were selected to participate in this study. Subjects' characteristics are provided in Table 1. Subjects were informed about the nature and risks of the experimental procedures before their
Table 1 Subjects' characteristics $(n=10)$

\begin{tabular}{|c|c|}
\hline \multicolumn{2}{|l|}{ Characteristics } \\
\hline Age (years) & $23 \pm 3$ \\
\hline Height (m) & $1.83 \pm 0.04$ \\
\hline Body mass (kg) & $72.5 \pm 9.6$ \\
\hline BMI $\left(\mathrm{kg} \mathrm{m}^{-2}\right)$ & $21.7 \pm 1.9$ \\
\hline Body fat percentage (\%) & $9.8 \pm 2.4$ \\
\hline Fat free mass $(\mathrm{kg})$ & $65.3 \pm 7.9$ \\
\hline Basal plasma glucose $\left(\mathrm{mmol} \mathrm{l}^{-1}\right)$ & $5.1 \pm 0.3$ \\
\hline Plasma glucose $_{120 \min }\left(\mathrm{mmol} \mathrm{l}^{-1}\right)$ & $3.9 \pm 1.1$ \\
\hline Basal plasma insulin $\left(\mathrm{mU} \mathrm{l}^{-1}\right)$ & $9.0 \pm 2.6$ \\
\hline $\mathrm{HbA}_{1} \mathrm{c}(\%)$ & $5.2 \pm 0.2$ \\
\hline $\mathrm{VO}_{2} \max \left(\mathrm{ml} \mathrm{kg}^{-1} \min ^{-1}\right)$ & $59.8 \pm 5.6$ \\
\hline$W_{\max }(\mathrm{W})$ & $398 \pm 41$ \\
\hline
\end{tabular}

Values are expressed as means $\pm \mathrm{SD}$. Body mass index $(B M I)$ is calculated by dividing body mass by the square of the height.

Plasma glucose 120 min Plasma glucose concentration 120 min after ingesting 75 glucose in the oral glucose tolerance test

written informed consent were obtained. This study was approved by the local Medical Ethical Committee of the Academic Hospital Maastricht.

\section{Pretesting}

Subjects initially performed a continuous incremental cycling test on a cycle ergometer (LODE Instrument, Groningen, The Netherlands) to exhaustion to determine peak pulmonary oxygen uptake $\left(\mathrm{VO}_{2 \max }\right.$; Oxycon- $\beta$, Mijnhart, The Netherlands) and maximal workload capacity $\left(W_{\max }\right)$. After an overnight fast, body composition was assessed using the hydrostatic weighing method, with corrections made for residual lung volume via the helium dilution technique (Volugraph 2000, Mijnhart, Bunnik, Netherlands). Body-fat percentage was calculated using Siri's [31] equation. To assess whole-body insulin sensitivity an oral glucose tolerance test was performed in each subject according to the World Health Organization criteria [2]. In addition, insulin resistance was estimated using the homeostasis model assessment for insulin resistance or HOMA-IR index [23].

Diet and activity before testing

All subjects were instructed to maintain their usual dietary and physical activity patterns throughout the entire experimental period. In addition, they filled out a food intake diary for 2 days before the first exercise trial to keep their dietary intake as identical as possible before the other trials. Subjects refrained from heavy physical labor and exercise training for 3 days before each trial. Dietary analyses showed no differences in energy intake during the days before each of the trials with an average energy intake of 
$12.7 \pm 2.4 \mathrm{MJ}$, with $57 \pm 7,28 \pm 5$, and $15 \pm 3 \%$ of the energy intake (energy $\%$ ) derived from carbohydrate, fat, and protein, respectively. The evening before each trial, subjects received the same standardized meal $\left(41.2 \mathrm{~kJ} \mathrm{~kg} \mathrm{bw}^{-1}\right.$; containing 72,11 , and 17 energy $\%$ carbohydrate, fat, and protein, respectively).

\section{Experimental trials}

Each subject performed three trials, separated by at least 1 week: two experimental trials (CON: control vs CHO: carbohydrate) and an acetate correction trial (Fig. 1). Each trial consisted of $60 \mathrm{~min}$ of resting measurements, followed by $180 \mathrm{~min}$ of cycling at $50 \% W_{\max }$. In the main trials, an $\left[\mathrm{U}^{13}{ }^{13} \mathrm{C}\right]$ palmitate and $\left[6,6-{ }^{2} \mathrm{H}_{2}\right]$ glucose tracer were infused continuously at rest and during exercise with breath and blood samples collected at regular intervals. Muscle biopsy samples were collected before and immediately after exercise. In the carbohydrate supplementation trial (CHO), plasma FFA availability was reduced, and plasma glucose availability was augmented through carbohydrate ingestion. To allow for a continuous supply of glucose from the gut, subjects ingested an $8 \%$ CHO solution every 20 min during exercise at the rate of $0.7 \mathrm{~g} \mathrm{CHO} \mathrm{kg}^{-1} \mathrm{~h}^{-1}$, as recommended by the American College of Sports Medicine [1]. In the control trial, a placebo water drink was provided (CON). In a third trial, $\left[1,2-{ }^{13} \mathrm{C}\right]$ acetate was infused continuously at rest and during exercise, and only breath samples were collected. Both the CON and acetate trials were performed in an overnight fasted state. The acetate recovery factor was used to accurately correct $\left[\mathrm{U}_{-}{ }^{13} \mathrm{C}\right]$ palmitate oxidation rates for carbon label retention in the bicarbonate pool(s) and by way of isotopic exchange reactions in the TCA-cycle for each subject [40].

Protocol

After an overnight fast, subjects arrived at the laboratory at 8:00 A.M. by car or public transportation. After $30 \mathrm{~min}$ of supine rest, a percutaneous muscle biopsy was taken from the vastus lateralis muscle [3]. A Teflon catheter (Baxter, Utrecht, The Netherlands) was inserted into an antecubital vein of one arm for blood sampling, another catheter was inserted in the antecubital vein of the contralateral arm for isotope infusion. Thereafter, a resting blood sample was taken and expired breath samples were collected into vacutainer tubes. Subsequently, subjects were administered a single intravenous dose of $\mathrm{NaH}^{13} \mathrm{CO}_{3}\left(0.06375 \mathrm{mg} \mathrm{kg}^{-1}\right)$, to prime the bicarbonate pool(s), followed by a $\left[6,6{ }^{2} \mathrm{H}_{2}\right]$ glucose prime $\left(13.5 \mu \mathrm{mol} \mathrm{kg}{ }^{-1}\right)$. Thereafter, a continuous infusion of $\left[6,6{ }^{2} \mathrm{H}_{2}\right]$ glucose $\left(0.3 \mu \mathrm{mol} \mathrm{kg} \mathrm{kg}^{-1}\right)$ and [U- $\left.{ }^{13} \mathrm{C}\right]$ palmitate $\left(0.01 \mu \mathrm{mol} \mathrm{kg}{ }^{-1} \mathrm{~min}^{-1}\right.$; or $\left[1,2-{ }^{13} \mathrm{C}\right]$ acetate in the acetate recovery trial) was started $(t=0 \mathrm{~min})$ via a calibrated IVAC pump (IVAC 560, San Diego, CA) and continued for $4 \mathrm{~h}$. At $t=60 \mathrm{~min}$, an initial drink bolus $\left(7 \mathrm{ml} \mathrm{kg}^{-1}\right)$ was given, and then nine more drink boluses $\left(2.5 \mathrm{ml} \mathrm{kg}^{-1}\right)$ were given at $t=80,100,120,140,160,180$, 200,220 , and $240 \mathrm{~min}$ of either an $8 \%$ carbohydrate solution or a placebo. At $t=60 \mathrm{~min}$, subjects started to exercise on a cycle ergometer at a workload of $50 \% W_{\max }$ for 3 h. Expired $\mathrm{VO}_{2}$ and $\mathrm{VCO}_{2}$ were measured (Oxycon- $\beta$ ) at rest and throughout exercise for $5 \mathrm{~min}$ every $20 \mathrm{~min}$ before sampling of blood and expired breath collection. Immediately after cessation of exercise, a second muscle
Fig. 1 Schematic of study protocol. After an initial resting blood, breath, and muscle biopsy sample, a continuous infusion with $\left[\mathrm{U}_{-}{ }^{13} \mathrm{C}\right]$ palmitate and $6,6-{ }^{2} \mathrm{H}_{2}$ glucose was started for $240 \mathrm{~min}$. At rest and during $3 \mathrm{~h}$ of cycling at $50 \%$ of $W_{\max }$ substrate use was assessed with (CHO trial) and without (CON trial) carbohydrate supplementation

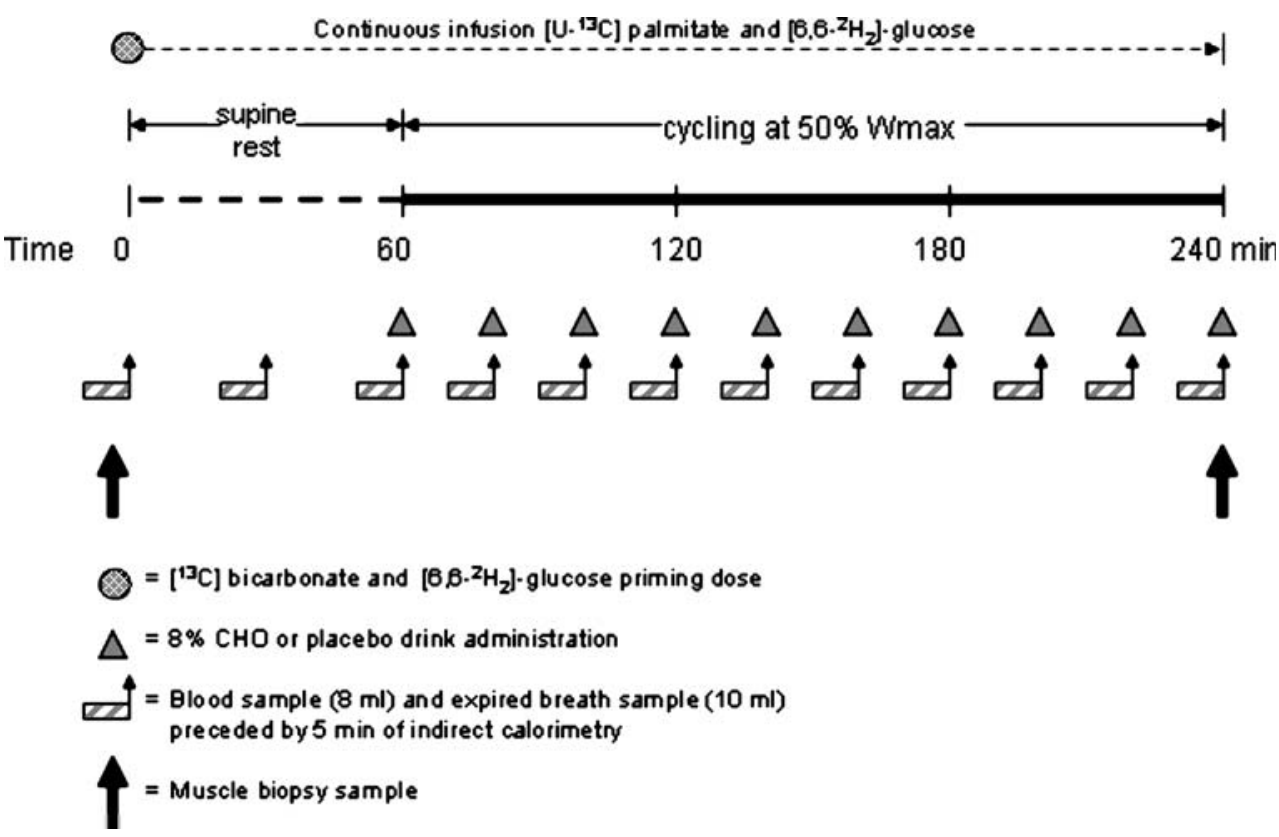


biopsy was taken $(t=240 \mathrm{~min})$. Breath and blood samples were collected at $t=0,30$, and $60 \mathrm{~min}$ (during rest) and at $t=80,100,120,140,160,180,200,220$, and $240 \mathrm{~min}$ (during exercise).

\section{Beverages}

In the $\mathrm{CHO}$ trial, subjects received a beverage volume of $2.5 \mathrm{ml} \mathrm{kg}^{-1}$ every $20 \mathrm{~min}$ to ensure a given dose of $0.7 \mathrm{~g}$ $\mathrm{CHO} \mathrm{kg}{ }^{-1}$ (50\% as glucose and $50 \%$ as maltodextrin) every hour. Repeated boluses were administered to enable a continuous supply of glucose in the circulation, preventing perturbations in $\left[6,6-{ }^{2} \mathrm{H}_{2}\right]$ glucose enrichment. In the CON trial, a sweetened placebo drink, which contained no carbohydrate, was provided. Glucose and maltodextrin were obtained from AVEBE (Veendam, The Netherlands). To make the taste comparable in all experiments, beverages were uniformly flavored by adding $0.2 \mathrm{~g}$ sodium-saccharine solution $(25 \% w / w), 1.8 \mathrm{~g}$ citric acid solution $(50 \% w / w)$, and $5 \mathrm{~g}$ of cream vanilla flavor (Numico Research, Wageningen, The Netherlands) for each liter of beverage. Experiments were performed in a randomized order, with test drinks provided in a double-blind fashion.

\section{Tracer infusion}

Infusion rates of $\left[\mathrm{U}^{13} \mathrm{C}\right]$ palmitate and $\left[6,6-{ }^{2} \mathrm{H}_{2}\right]$ glucose averaged $7.3 \pm 0.8$ and $817.5 \pm 30.4 \mathrm{nmol} \mathrm{kg} \mathrm{min}^{-1}$, respectively, in the $\mathrm{CON}$ and $\mathrm{CHO}$ trial. At the onset of exercise, $\left[\mathrm{U}_{-}{ }^{13} \mathrm{C}\right]$ palmitate infusion rates were doubled $\left(14.6 \pm 1.6 \mathrm{nmol} \mathrm{kg} \mathrm{min}^{-1}\right)$. In the acetate recovery trial, a corresponding amount of ${ }^{13} \mathrm{C}$ was infused, resulting in an average $\left[1,2-{ }^{13} \mathrm{C}\right]$ acetate infusion rate of $61.6 \pm 2.4$ and $123 \pm 5 \mathrm{nmol} \mathrm{kg}^{-1} \mathrm{~min}^{-1}$ at rest and during exercise, respectively. Palmitate, glucose, and acetate tracer concentrations in the infusates averaged $1.03 \pm 0.07,64.8 \pm 7.2$, and $4.74 \pm 0.18 \mathrm{mmol} \mathrm{l}^{-1}$, respectively.

Blood- and breath-sample analysis

Blood samples $(7 \mathrm{ml})$ were collected in ethylenediamine tetraacetic acid (EDTA)-containing tubes and centrifuged at $1,000 \times \mathrm{g}$ for $10 \mathrm{~min}$ at $4^{\circ} \mathrm{C}$. Aliquots of plasma were frozen immediately in liquid nitrogen and stored at $-80^{\circ} \mathrm{C}$. Plasma glucose (Uni Kit III, Roche, Basel, Switzerland), lactate [16], FFA (NEFA-C, Wako Chemicals, Neuss, Germany), free glycerol (148270, Roche Diagnostics, Indianapolis, IN), and triglyceride (TG; GPO-trinder 337B, Sigma Diagnostics, St. Louis, MO) concentrations were analyzed with a COBAS semi-automatic analyzer (Roche).

Expired breath samples were analyzed for ${ }^{13} \mathrm{C} /{ }^{12} \mathrm{C}$ ratio by gas chromatography continuous flow isotope ratio mass spectrometry (GC-IRMS; Finnigan MAT 252, Bremen,
Germany). For determination of plasma palmitate and FFA kinetics, FFA were extracted from plasma, isolated by thin-layer chromatography, and derivatized to their methyl esters. Palmitate concentration was determined on an analytical gas chromatograph with flame ionization detection using heptadecanoic acid as an internal standard and on average comprised $26 \pm 2$ and $24 \pm 3 \%$ of total FFA for the $\mathrm{CON}$ and $\mathrm{CHO}$ trials, respectively. Isotope tracer/ tracee ratio of $\left[\mathrm{U}-{ }^{13} \mathrm{C}\right]$ palmitate was determined using $\mathrm{GC}$ combustion IRMS (Finnigan MAT 252). Plasma glucose was first extracted with chloroform-methanol-water and derivatization was performed with butylboronic acid and acetic anhydride as described previously [27]. After derivatization, plasma $\left[6,6-{ }^{2} \mathrm{H}_{2}\right]$ glucose enrichment was determined by electron ionization GC-MS (Finnigan INCOS-XL). Glucose (Uni Kit III, Roche) and acetate (Kit 148261, Boehringer) concentrations in the infusates were determined with the COBAS FARA.

\section{Calculations}

From respiratory measurements, total fat and carbohydrate oxidation rates were calculated using the nonprotein respiratory quotient [26].

Fat oxidation rate $=1.695 \mathrm{VO}_{2}-1.701 \mathrm{VCO}_{2}$

Carbohydrate oxidation rate $=4.585 \mathrm{VCO}_{2}-3.22 \mathrm{VO}_{2}$

with $\mathrm{VO}_{2}$ and $\mathrm{VCO}_{2}$ in liters per minute $\left(1 \mathrm{~min}^{-1}\right)$ and oxidation rates in grams per minute $\left(\mathrm{g} \mathrm{min}^{-1}\right)$. Breath and plasma enrichments are expressed as tracer/tracee ratios (TTR);

$\mathrm{TTR}=\left({ }^{13} \mathrm{C} /{ }^{12} \mathrm{C}\right)_{\mathrm{sa}}-\left({ }^{13} \mathrm{C} /{ }^{12} \mathrm{C}\right)_{b k}$

in which sa indicates sample and bk indicates background value. Rate of palmitate and glucose appearance $\left(R_{\mathrm{a}}\right)$ and disappearance $\left(R_{\mathrm{d}}\right)$ were calculated using the single-pool nonsteady-state Steele [32] equations adapted for stable isotope methodology as described elsewhere [49]. As such, plasma palmitate and glucose $R_{\mathrm{d}}$ were calculated by correcting the $R_{\mathrm{a}}$ for the time-dependent changes in plasma metabolite concentration.

$R_{a}=\frac{F-V\left[\left(C_{2}+C_{1}\right) / 2\right]\left[\left(E_{2}-E_{1}\right) /\left(t_{2}-t_{1}\right)\right]}{\left(E_{2}+E_{1}\right) / 2}$

$R_{d}=R_{a}-V\left(\frac{C_{2}-C_{1}}{t_{2}-t_{1}}\right)$ 
where $F$ is the infusion rate $\left(\mu \mathrm{mol} \mathrm{kg} \mathrm{kg}^{-1} \mathrm{~min}^{-1}\right)$; $V$ is the distribution volume for palmitate or glucose $(40$ and $160 \mathrm{ml}$ $\mathrm{kg}^{-1}$, respectively); $C_{1}$ and $C_{2}$ are the palmitate or glucose concentrations $\left(\mathrm{mmol} \mathrm{l}^{-1}\right)$ at time $1\left(t_{1}\right)$ and $2\left(t_{2}\right)$, respectively, and $E_{2}$ and $E_{1}$ are the plasma palmitate or glucose enrichments (TTR) at time 1 and 2, respectively. ${ }^{13} \mathrm{CO}_{2}$ production $\left(\operatorname{Pr}^{13} \mathrm{CO}_{2}\right.$; mol min $\left.{ }^{-1}\right)$ from the infused palmitate tracer was calculated as:

$\operatorname{Pr}^{13} \mathrm{CO}_{2}=\left(\mathrm{TTR}_{\mathrm{CO}_{2}} V \mathrm{CO}_{2}\right) /(k \mathrm{Ar})$

where $\mathrm{TTR}_{\mathrm{CO} 2}$ is the breath ${ }^{13} \mathrm{C} /{ }^{12} \mathrm{C}$ ratio at a given time point, $\mathrm{VCO}_{2}$ is the carbon dioxide production $\left(1 \mathrm{~min}^{-1}\right), k$ is the volume of $1 \mathrm{~mol}$ of $\mathrm{CO}_{2}\left(22.41 \mathrm{~mol}^{-1}\right)$, and $\mathrm{Ar}$ is the fractional ${ }^{13} \mathrm{C}$ label recovery in breath $\mathrm{CO}_{2}$ observed after the infusion of labeled acetate [30] and calculated as:

$A r=\left(\mathrm{TTR}_{\mathrm{CO}_{2}} V \mathrm{CO}_{2} / k 2 F\right)$

where $F$ is the infusion rate of $\left[1,2-{ }^{13} \mathrm{C}\right]$ acetate (mol

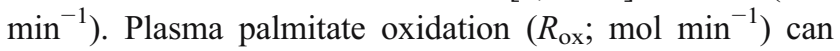
subsequently be calculated as:

$R_{\text {ox }}$ palmitate $=R_{\mathrm{d}}$ palmitate $\left(\operatorname{Pr}^{13} \mathrm{CO}_{2} / F 16\right)$

where $R_{\mathrm{d}}$ palmitate is the rate of palmitate disappearance $\left(\mathrm{mol} \mathrm{min}{ }^{-1}\right) ; F$ is the palmitate infusion rate $\left(\mathrm{mol} \mathrm{min}^{-1}\right)$, and 16 is the number of carbon atoms in palmitate. Total plasma FFA oxidation was calculated by dividing palmitate oxidation rates by the fractional contribution of plasma palmitate to total plasma FFA concentration. Muscle derived TG use was estimated by subtracting plasma FFA oxidation from total fat oxidation. However, it should be noted that the indirect stable isotope methodology does not differentiate between muscle- and lipoprotein-derived TG use. However, the contribution of lipoprotein-derived TG oxidation to total energy expenditure is assumed to be of relative minor quantitative importance, especially in an overnight-fasted state [37].

In a previous study, where we applied both an $\left[\mathrm{U}_{-}{ }^{13} \mathrm{C}\right]$ and $\left[6,6-{ }^{2} \mathrm{H}_{2}\right]$ glucose tracer [18] during moderate intensity exercise, it was shown that the percentage of plasma glucose $R_{\mathrm{d}}$ that was oxidized varied between $96-100 \%$. Therefore, plasma glucose oxidation rate during exercise was calculated as:

$R_{\text {ox }}$ plasma glucose $=R_{\mathrm{d}}$ plasma glucose $($ during exercise $)$

Therefore, muscle glycogen oxidation was calculated by subtracting plasma glucose oxidation from total carbohydrate oxidation.
Muscle-sample analyses

Muscle tissue samples were freed from any visible nonmuscle material and rapidly frozen in liquid nitrogen. About $15 \mathrm{mg}$ of each muscle sample was frozen in liquid nitrogen-cooled isopentane and embedded in Tissue-Tek (Sakura Finetek, Zoeterwoude, The Netherlands). Multiple serial sections $(5 \mu \mathrm{m})$ from all biopsy samples were thaw mounted together per subject on uncoated, precleaned glass slides and stained with either acid-Schiff (PAS) [29] or immunolabelled oil red $\mathrm{O}$ [21] to measure fiber-type-specific glycogen or intramyocellular lipid content, respectively. To determine the muscle-fiber typing, (type I vs type II), we performed a myosin adenosine $5^{\prime}$-triphosphatase stain [22]. As previously described, the applied fluorescence and bright field microscopy techniques represent semiquantitative methods that can be used to compare fiber-type-specific IMTG and glycogen content [39, 41, 43, 44]. Fiber-type-specific IMTG content was expressed as the fraction of the measured area that was stained with oil red O. For IMTG quantification, average lipid-droplet size was calculated by dividing the total number of lipid aggregates by the total area measured. Mixed musclelipid content, lipid-droplet size, and lipid-droplet density were determined by calculating the average value in the type I and type II muscle fibers, with a correction for the relative area occupied by each fiber type within each field of view of each muscle cross-section, within each individual subject. The oil red $\mathrm{O}$ epifluorescence signal was recorded for each muscle fiber resulting, on average, in a total of $71 \pm 19$ muscle fibers analyzed for each muscle cross-section ( $45 \pm 14$ type I, $26 \pm 10$ type II) per subject. The PAS bright-field images were converted post hoc into eight-bit grayscale values to quantify glycogen. The mean optical density of the PAS-stained muscle fibers were determined by averaging the optical density measured in every pixel in the cell, corrected for the mean optical density of the background stain, containing no muscle fibers. For PAS analysis, on average per subject, a total of $151 \pm 61$ muscle fibers were analyzed for each muscle cross-section ( $92 \pm 32$ type I, $59 \pm 26$ type II).

\section{Statistics}

All data are expressed as mean \pm SD. Before statistical analysis, data normality was confirmed at $P>0.05$ using the Kolmogorov-Smirnov test on log-transformed raw data. To compare tracer kinetics, substrate utilization rates, IMTG contents, and/or plasma metabolite concentrations over time between trials, a two-way repeated measures analysis of variance was applied. When a significant $F$ ratio was obtained, post hoc analyses were completed using a Student-Newman-Keuls test. For nontime-dependent variables, a Student's $t$ test for paired observations was used. Statistical significance was accepted at $P<0.05$. 


\section{Results}

Plasma metabolite and hormone concentrations

Plasma FFA, triacylglycerol (TG), glycerol, glucose, lactate, and insulin concentrations over time during exercise are shown in Fig. 2. There were no differences in plasma FFA and glycerol between trials at rest or during the first
40 min of exercise (Fig. 2a,c). However, at all time points after $60 \mathrm{~min}$, plasma FFA and glycerol concentrations increased over time in both trials, but levels remained significantly lower in the $\mathrm{CHO}$ vs $\mathrm{CON}$ trial $(P<0.01)$. Plasma TG levels declined throughout exercise in both trials but were significantly higher in the $\mathrm{CHO}$ vs the $\mathrm{CON}$ trial $(P<0.05$; Fig. 2b). Plasma glucose concentrations increased in the $\mathrm{CHO}$ trial at the initiation of carbohydrate
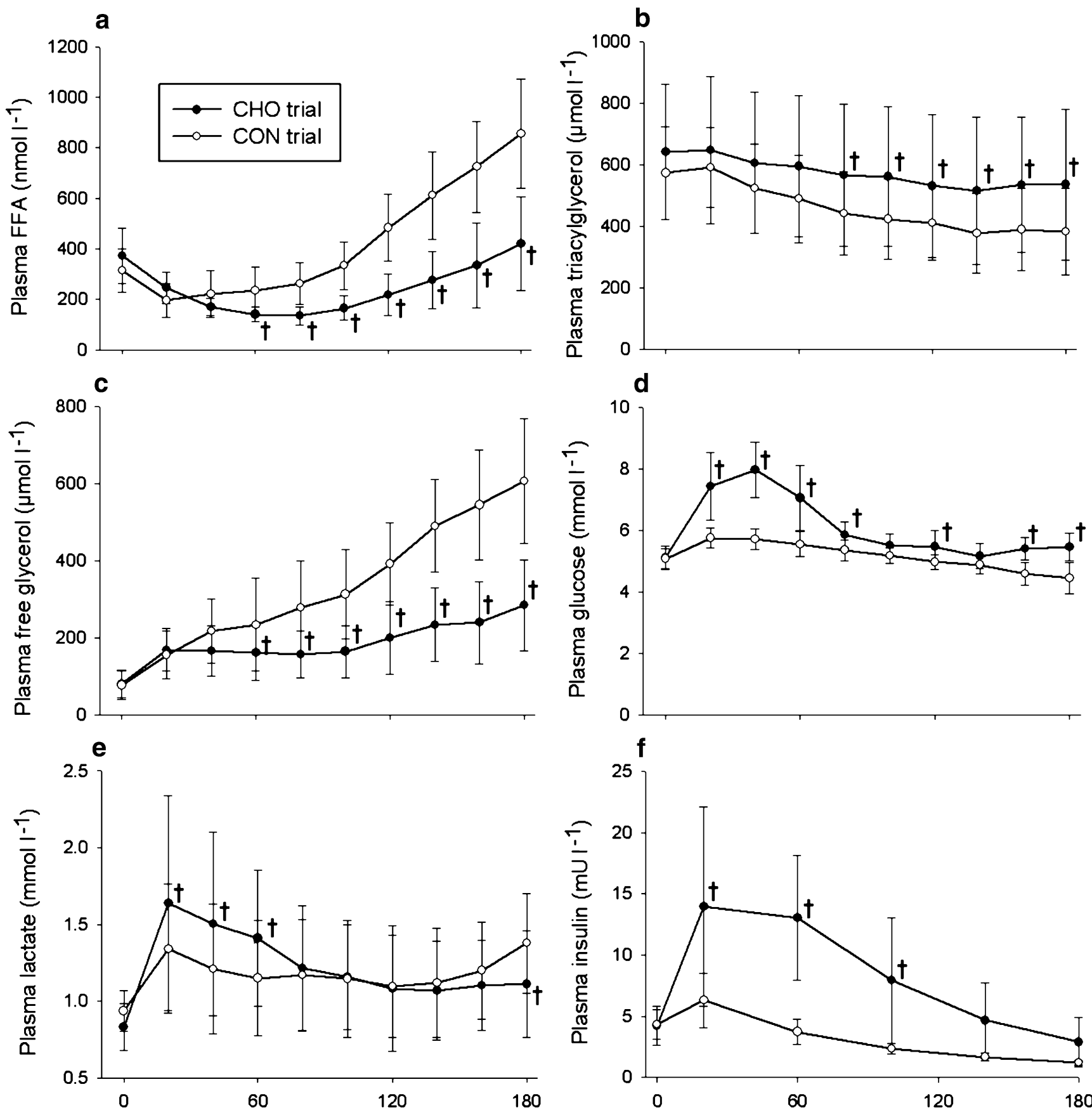

Time during exercise $(\mathrm{min})$

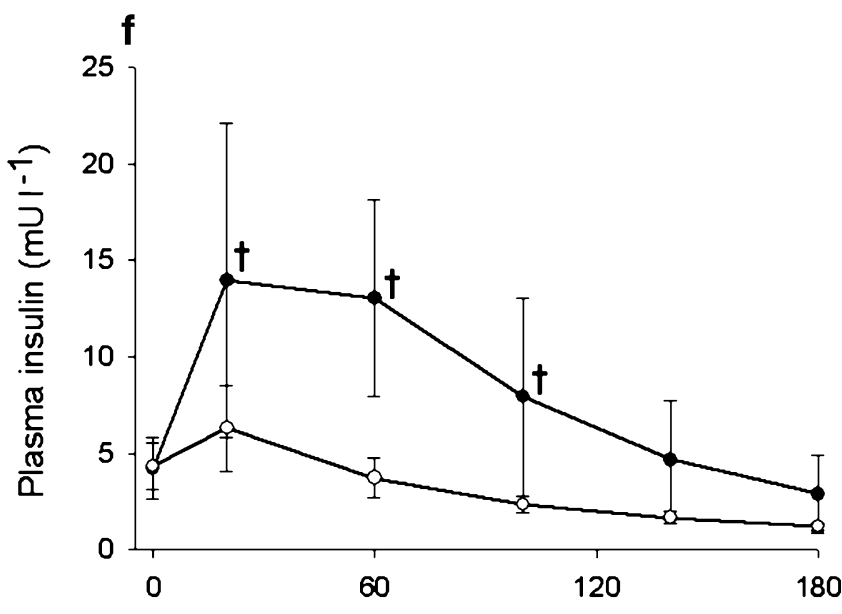

Time during exercise ( $\mathrm{min})$

Fig. 2 Plasma metabolite concentrations during $3 \mathrm{~h}$ of cycling at $50 \% W_{\max }$ in CON and CHO trials. Values are means $\pm \mathrm{SD}, n=10$. Crosses, significantly different than CON trial $(P<0.05)$ 


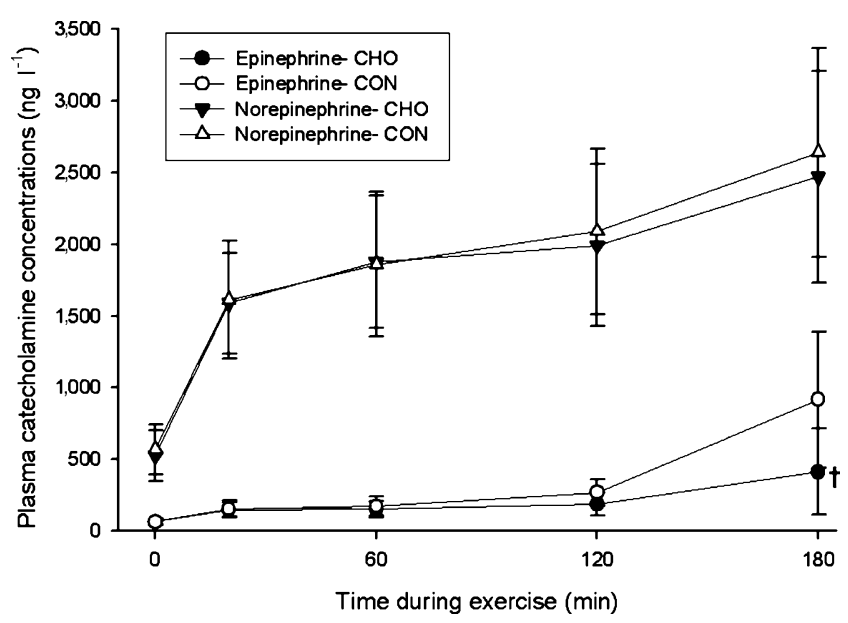

Fig. 3 Plasma catecholamine concentrations during $3 \mathrm{~h}$ of cycling at $50 \% W_{\max }$ in CON and CHO trials. Values are means $\pm \mathrm{SD}, n=10$. Crosses, significantly different from the CON trial $(P<0.05)$

ingestion and were significantly higher in the $\mathrm{CHO}$ vs $\mathrm{CON}$ trial $(P<0.05$; Fig. 2d). Over the last hour of exercise, plasma glucose steadily declined in both trials but remained significantly higher in the $\mathrm{CHO}$ vs $\mathrm{CON}$ trial. Plasma insulin levels in the $\mathrm{CHO}$ trial significantly increased during the initial $90 \mathrm{~min}$ of exercise as compared to $\mathrm{CON}$ $(P<0.05$; Fig. 2f). Thereafter, plasma insulin steadily declined in both trials. Plasma lactate concentrations increased above baseline levels, with plasma lactate concentrations being greater in the $\mathrm{CHO}$ vs $\mathrm{CON}$ trial (Fig. 2e). In contrast, during the latter stages of exercise, significantly higher plasma lactate levels were observed in the CON vs
CHO trial. Plasma norepinephrine concentrations increased threefold within the first $20 \mathrm{~min}$ of exercise and continued to rise throughout the exercise period in both trials, with no significant differences between trials (Fig. 3). Plasma epinephrine levels increased gradually in both trials during the first $2 \mathrm{~h}$ of exercise, after which, levels increased substantially $(P<0.001$; Fig. 3$)$. However, in the CHO trial, there was an attenuated increase in epinephrine, resulting in significantly $(P<0.05)$ lower concentrations vs CON.

\section{Plasma tracer kinetics}

As plasma FFA and glucose concentrations varied over time in both trials (Fig. 2a,d), nonsteady-state Steele [32] equations were applied to calculate tracer kinetics. At rest, tracer kinetics did not differ between trials as carbohydrate supplementation did not start until the onset of exercise. At rest, plasma glucose $R_{\mathrm{a}}$ and $R_{\mathrm{d}}$ averaged $14.9 \pm 1.6$ and $15.0 \pm 1.8 \mu \mathrm{mol} \mathrm{kg} \mathrm{min}^{-1}$, respectively. Resting palmitate $R_{\mathrm{a}}, R_{\mathrm{d}}$, and $R_{\mathrm{ox}}$ averaged $1.92 \pm 0.43,1.89 \pm 0.55$, and $0.74 \pm$ $0.22 \mu \mathrm{mol} \mathrm{kg} \mathrm{kgin}^{-1}$, respectively, with $38 \pm 4 \%$ of palmitate $R_{\mathrm{a}}$ being oxidized. The onset of exercise significantly elevated plasma glucose and palmitate $R_{\mathrm{a}}$, $R_{\mathrm{d}}$, and/or $R_{\text {ox }}$ (Table 2). Plasma glucose $R_{\mathrm{a}}$ and $R_{\mathrm{d}}$, and palmitate $R_{\mathrm{a}}, R_{\mathrm{d}}$, and $R_{\mathrm{ox}}$ increased continuously during the exercise in both trials (Table 2). During the entire exercise period, average glucose $R_{\mathrm{a}}$ and $R_{\mathrm{d}}$ was $49 \pm 9 \%$ greater in the CHO compared with the CON trial $(P<0.05$; Table 2$)$. In contrast, plasma palmitate $R_{\mathrm{a}}, R_{\mathrm{d}}$, and $R_{\mathrm{ox}}$ was $41 \pm 12 \%$ lower during exercise in the $\mathrm{CHO}$ vs $\mathrm{CON}$ trial $(P<0.05$;

Table 2 Tracer kinetics and respiratory measures during exercise

\begin{tabular}{|c|c|c|c|c|c|c|c|c|}
\hline & \multicolumn{2}{|l|}{ First hour } & \multicolumn{2}{|l|}{ Second hour } & \multicolumn{2}{|l|}{ Third hour } & \multicolumn{2}{|c|}{ Exercise average } \\
\hline & $\mathrm{CON}$ & $\mathrm{CHO}$ & $\mathrm{CON}$ & $\mathrm{CHO}$ & $\mathrm{CON}$ & $\mathrm{CHO}$ & $\mathrm{CON}$ & $\mathrm{CHO}$ \\
\hline \multicolumn{9}{|l|}{ Glucose } \\
\hline$R_{\mathrm{a}}\left(\mu \mathrm{mol} \mathrm{kg}{ }^{-1} \min ^{-1}\right)$ & $21.1 \pm 2.7$ & $46.8 \pm 9.6^{\mathrm{a}}$ & $28.8 \pm 4.8$ & $55.8 \pm 6.8^{\mathrm{a}}$ & $38.1 \pm 7.5$ & $72.9 \pm 8.2^{\mathrm{a}}$ & $30.4 \pm 4.7$ & $59.9 \pm 7.2^{\mathrm{a}}$ \\
\hline$R_{\mathrm{d}}\left(\mu \mathrm{mol} \mathrm{kg}{ }^{-1} \min ^{-1}\right)$ & $21.9 \pm 3.1$ & $48.3 \pm 12.3^{\mathrm{a}}$ & $30.3 \pm 7.9$ & $60.0 \pm 11.2^{\mathrm{a}}$ & $39.5 \pm 7.2$ & $72.9 \pm 8.5^{\mathrm{a}}$ & $31.7 \pm 4.7$ & $61.9 \pm 7.3^{\mathrm{a}}$ \\
\hline \multicolumn{9}{|l|}{ Palmitate } \\
\hline$R_{\mathrm{a}}\left(\mu \mathrm{mol} \mathrm{kg}{ }^{-1} \min ^{-1}\right)$ & $2.49 \pm 0.80$ & $2.03 \pm 0.40^{\mathrm{a}}$ & $3.55 \pm 0.78$ & $1.97 \pm 0.57^{\mathrm{a}}$ & $6.43 \pm 0.89$ & $3.60 \pm 1.92^{\mathrm{a}}$ & $4.36 \pm 0.71$ & $2.59 \pm 0.70^{\mathrm{a}}$ \\
\hline$R_{\mathrm{d}}\left(\mu \mathrm{mol} \mathrm{kg}{ }^{-1} \min ^{-1}\right)$ & $2.48 \pm 0.79$ & $2.06 \pm 0.40^{\mathrm{a}}$ & $3.50 \pm 0.79$ & $1.96 \pm 0.56^{\mathrm{a}}$ & $6.36 \pm 0.88$ & $3.57 \pm 1.34^{\mathrm{a}}$ & $4.32 \pm 0.70$ & $2.58 \pm 0.69^{\mathrm{a}}$ \\
\hline$R_{\mathrm{ox}}\left(\mu \mathrm{mol} \mathrm{kg}{ }^{-1} \min ^{-1}\right)$ & $2.28 \pm 0.73$ & $1.84 \pm 0.42^{\mathrm{a}}$ & $3.49 \pm 0.72$ & $1.91 \pm 0.68^{\mathrm{a}}$ & $6.35 \pm 0.73$ & $3.62 \pm 1.38^{\mathrm{a}}$ & $4.26 \pm 0.59$ & $2.53 \pm 0.77^{\mathrm{a}}$ \\
\hline$\% R_{\mathrm{a}}$ ox & $91.5 \pm 5.9$ & $90.9 \pm 8.6$ & $98.7 \pm 5.83$ & $95.6 \pm 8.8$ & $99.4 \pm 7.8$ & $99.8 \pm 7.0$ & $97.2 \pm 6.2$ & $96.0 \pm 6.8$ \\
\hline Ac recovery & $81.7 \pm 5.7$ & - & $86.5 \pm 4.7$ & - & $86.2 \pm 4.1$ & - & $85.8 \pm 3.9$ & - \\
\hline \multicolumn{9}{|l|}{ Respiratory measures } \\
\hline $\mathrm{VO}_{2}(\mathrm{ml})$ & $2,666 \pm 91$ & $2,690 \pm 90$ & $2,713 \pm 88$ & $2,709 \pm 98$ & $2,773 \pm 93$ & $2,772 \pm 109$ & $2,717 \pm 89$ & $2,724 \pm 97$ \\
\hline $\mathrm{VCO}_{2}(\mathrm{ml})$ & $2,361 \pm 81$ & $2,412 \pm 76$ & $2,336 \pm 76$ & $2,424 \pm 84^{\mathrm{a}}$ & $2,327 \pm 88$ & $2,453 \pm 94^{\mathrm{a}}$ & $2,342 \pm 79$ & $2,430 \pm 83^{\mathrm{a}}$ \\
\hline RER & $0.89 \pm 0.01$ & $0.90 \pm 0.01$ & $0.86 \pm 0.01$ & $0.90 \pm 0.01^{\mathrm{a}}$ & $0.84 \pm 0.01$ & $0.89 \pm 0.01^{\mathrm{a}}$ & $0.86 \pm 0.01$ & $0.89 \pm 0.01^{\mathrm{a}}$ \\
\hline
\end{tabular}

Values are expressed as means $\pm \mathrm{SD}, n=10$. Tracer kinetics during each hour of exercise and averaged during $3 \mathrm{~h}$ of cycling at $50 \% W_{\text {max }}$ in the CON and CHO trial.

$R_{a}$ Rate of appearance; $R_{d}$ rate of disappearance; $R_{o x}$ rate of oxidation; $\% R_{a}$ ox $\% \mathrm{R}_{\mathrm{a}}$ palmitate oxidized; Ac recovery fraction $1,2-{ }^{13} \mathrm{C}$ acetate label recovery in expired $\mathrm{CO}_{2}$

${ }^{\text {a }}$ Significantly different compared with the CON trial $(P<0.05)$ 
Table 2). Acetate label recovery maintained a constant value during exercise and averaged $86 \pm 4 \%$ of the acetate infusion rate. In a pilot experiment, we confirmed that carbohydrate supplementation does not affect acetate label recovery during exercise, which was in accordance to previous findings [44].

\section{Substrate source utilization at rest}

There were no differences in total resting energy expenditure ( $5.37 \pm 0.52$ vs $5.32 \pm 0.53 \mathrm{~kJ} \mathrm{~min}^{-1}$ in the $\mathrm{CON}$ and $\mathrm{CHO}$ trial, respectively) or substrate source utilization rates between trials. Total fat oxidation averaged $0.08 \pm 0.01 \mathrm{~g} \mathrm{~min}^{-1}$, contributing $58 \pm 6 \%$ to total energy expenditure. Plasma FFA oxidation rates averaged $0.061 \pm 0.011 \mathrm{~g} \mathrm{~min}^{-1}$, contributing $53 \pm 7$ to total energy expenditure at rest. The use of muscle- and/or lipoprotein-derived TG sources averaged $0.016 \pm 0.008 \mathrm{~g}$ $\min ^{-1}$ and contributed $7 \pm 20 \%$ to total energy expenditure. Total carbohydrate oxidation rates averaged $0.13 \pm 0.03 \mathrm{~g}$ $\min ^{-1}$, contributing $42 \pm 6 \%$ to total energy expenditure.

\section{Substrate source utilization during exercise}

The applied $50 \% W_{\max }$ workload resulted in subjects cycling at $199 \pm 21 \mathrm{~W}$, corresponding with a relative workload intensity of $63 \pm 1 \% \mathrm{VO}_{2 \max }$ From rest to exercise, energy expenditure increased tenfold. No differences in energy expenditure were observed over time or between trials $\left(57.3 \pm 5.9\right.$ and $57.8 \pm 6.4 \mathrm{~kJ} \mathrm{~min}^{-1}$ in the $\mathrm{CON}$ and $\mathrm{CHO}$ trial, respectively; Fig. 5). Total carbohydrate oxidation rates were significantly higher in the $\mathrm{CHO}$ vs the CON trial $\left(2.35 \pm 0.37\right.$ vs $1.97 \pm 0.33 \mathrm{~g} \mathrm{~min}^{-1}$, respectively; $P<0.001)$. Concomitantly, total fat oxidation rates were higher in the $\mathrm{CON}$ vs $\mathrm{CHO}$ trial $(0.62 \pm 0.12$ vs $0.48 \pm 0.16 \mathrm{~g} \mathrm{~min}^{-1}$, respectively; $\left.P<0.001\right)$. In the $\mathrm{CHO}$ trial, carbohydrate and fat oxidation contributed $66 \pm 6$ and $34 \pm 5 \%$ to total energy, respectively. In the CON trial, carbohydrate and fat oxidation contributed $56 \pm 5$ and $44 \pm$ $7 \%$ to total energy expenditure during exercise.

The use of specific substrate sources over time during exercise is illustrated in Fig. 4. The calculations for substrate source utilization in Figs. 4 and 5 commences at $40 \mathrm{~min}$ because of the nonsteady-state transition from rest to exercise. Plasma FFA and glucose oxidation rates increased over time in both trials $(P<0.01$; Fig. $4 \mathrm{a}, \mathrm{c})$. In contrast, the respective use of muscle- (and lipoprotein) derived TG and glycogen declined over time $(P<0.01$; Fig. 4b,d). Plasma glucose oxidation was significantly greater in the $\mathrm{CHO}$ vs $\mathrm{CON}$ trial and averaged $13.2 \pm 2.1$ vs $6.7 \pm 1.1 \mathrm{~kJ} \mathrm{~min}^{-1}$, respectively $(P<0.001$ : Fig. $4 \mathrm{c})$. Plasma FFA oxidation rates were substantially greater in the CON vs CHO trial and averaged $13.8 \pm 2.9$ vs $9.1 \pm 2.8 \mathrm{~kJ} \mathrm{~min}^{-1}$, respectively $(P<0.001$; Fig. 4a). No significant differences were observed in the use of muscle (and lipoprotein-derived) TG and glycogen over time between trials.

Figure 5 illustrates average substrate source utilization rates calculated over each consecutive hour of exercise. During the first hour of exercise, there were no differences in endogenous fat source utilization between trials. In contrast, plasma glucose oxidation rates were higher in the CHO trial, resulting in a $10 \pm 6 \%$ lower glycogen use compared with the CON trial $(P<0.05$; Fig. 5). During the latter stages of exercise, plasma glucose oxidation rates remained higher in the $\mathrm{CHO}$ vs $\mathrm{CON}$ trial, with no differences in muscle glycogen use between trials (Fig. 5). In the first hour, fat contributed nearly the same amount of energy in the CON and CHO trial, $36 \pm 6$ and $33 \pm 7 \%$, respectively. In contrast, during the second and third hour of exercise, total fat oxidation rates increased substantially, with greater fat use in the $\mathrm{CON}$ vs $\mathrm{CHO}$ trial. By the third hour, fat oxidation contributed $51 \pm 8 \%$ to total energy expenditure in the $\mathrm{CON}$ trial, whereas fat oxidation contributed only $36 \pm 9 \%$ in the $\mathrm{CHO}$ trial $(P<0.01$; Fig. 5$)$. In the $\mathrm{CHO}$ trial, the attenuated increase in fat oxidation rate during exercise was offset by a significant increase in total carbohydrate oxidation rate. Total carbohydrate oxidation rates during exercise averaged $1.97 \pm 0.33$ and $2.35 \pm$ $0.37 \mathrm{~g} \mathrm{~min}^{-1}$ in the $\mathrm{CON}$ and $\mathrm{CHO}$ trial, respectively $(P<0.01)$. As there were no differences in the average rate of glycogen utilization between treatments during the second and third hour of exercise (Figs. $4 \mathrm{~d}$ and 5), the increased carbohydrate use in the $\mathrm{CHO}$ trial was fully attributed to increases in plasma glucose oxidation over the last $2 \mathrm{~h}$ of cycling (Figs. 4c and 5). Muscle (and lipoprotein-derived) TG and glycogen use declined over time but did not differ between trials during the latter stages of exercise (Fig. 5).

\section{Skeletal muscle lipid content}

Preexercise fiber-type-specific muscle IMTG was not different between conditions and averaged $0.067 \pm 0.025$ and $0.018 \pm 0.010$ arbitrary units (AU) in type I and II muscle fibers, respectively. There was a significantly greater net decline in intramyocellular lipid content in the type I vs type II muscle fibers after exercise (Fig. 6a). No differences in the net decline in myocellular lipid content were observed between trials. Exercise resulted in a $76 \pm 21$ and $78 \pm 22 \%$ reduction in type I muscle-fiber lipid content in the $\mathrm{CHO}$ and $\mathrm{CON}$ trial, respectively $(P<0.01)$. Type II muscle-fiber lipid content was not significantly reduced after exercise and showed a net decline of $0.003 \pm 0.014$ and $0.008 \pm 0.0012 \mathrm{AU}$ in the $\mathrm{CHO}$ and $\mathrm{CON}$ trials, respectively $(P=\mathrm{NS})$. The observed decrease in type I muscle intramyocellular lipid content was attributed to significant decreases in both lipid-droplet size (preexercise, $0.560 \pm$ 0.150 ; vs postexercise, $0.359 \pm 0.152 \mu \mathrm{m}^{2}$ ) and lipid-droplet 


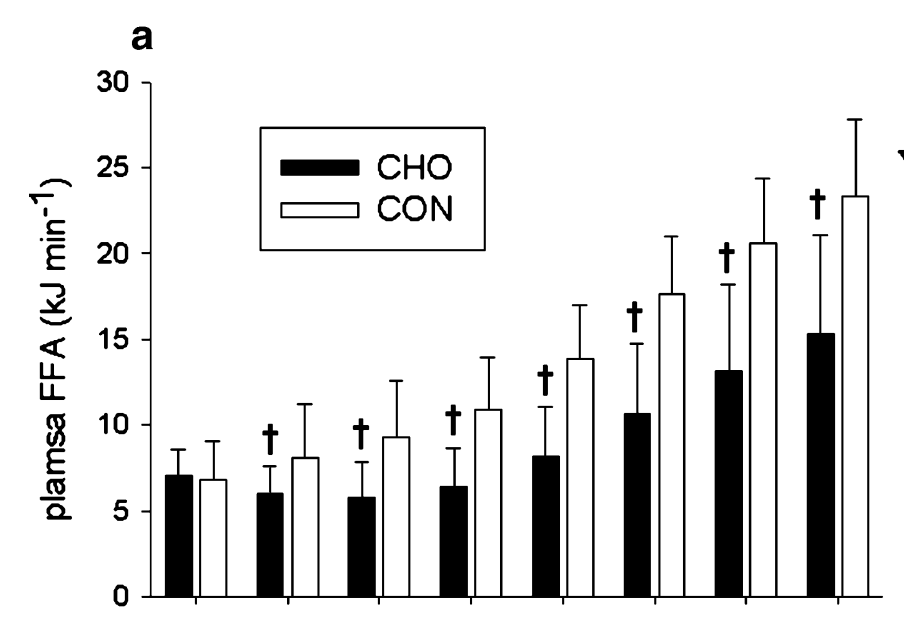

b
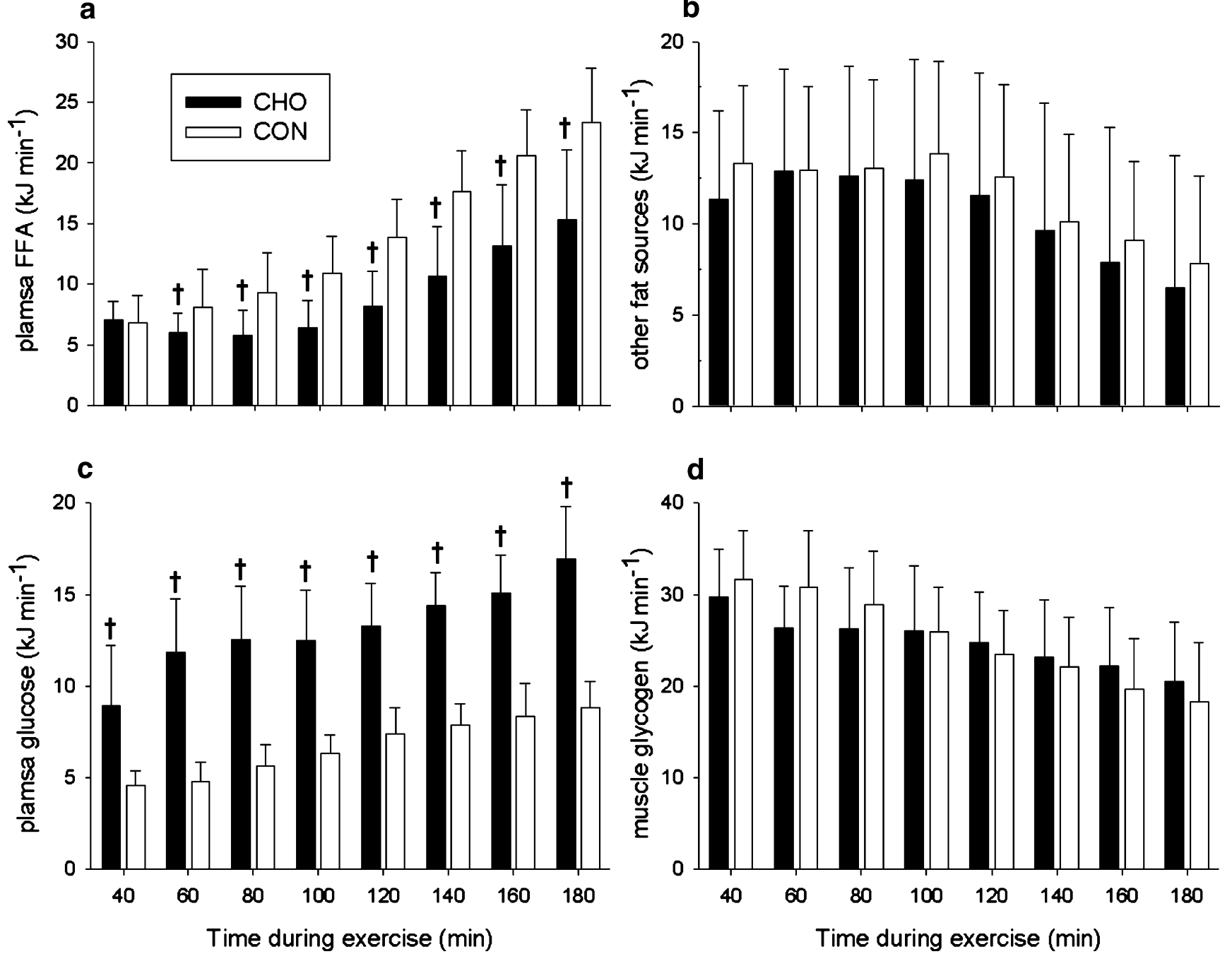

Fig. 4 a Plasma FFA, b other fat sources, c plasma glucose, and $\mathbf{d}$ muscle glycogen rate of oxidation (kJ min $\left.{ }^{-1}\right)$ during $3 \mathrm{~h}$ of cycling at $50 \%$ $W_{\max }$ in CON and CHO trials. Values are means $\pm \mathrm{SD}, n=10$. Crosses, significantly different from CON trial $(P<0.05)$

Fig. 5 Whole-body substrate source utilization $\left(\mathrm{kJ} \min ^{-1}\right)$ during the first, second, and third hour of cycling and averaged over the entire $3 \mathrm{~h}$, at $50 \%$ $W_{\text {max }}$ in the CON and CHO trial. Crosses, plasma FFA, other fat sources, total carbohydrate, and/ or plasma glucose and/or glycogen use significantly different from the CON trial $(P<0.05)$

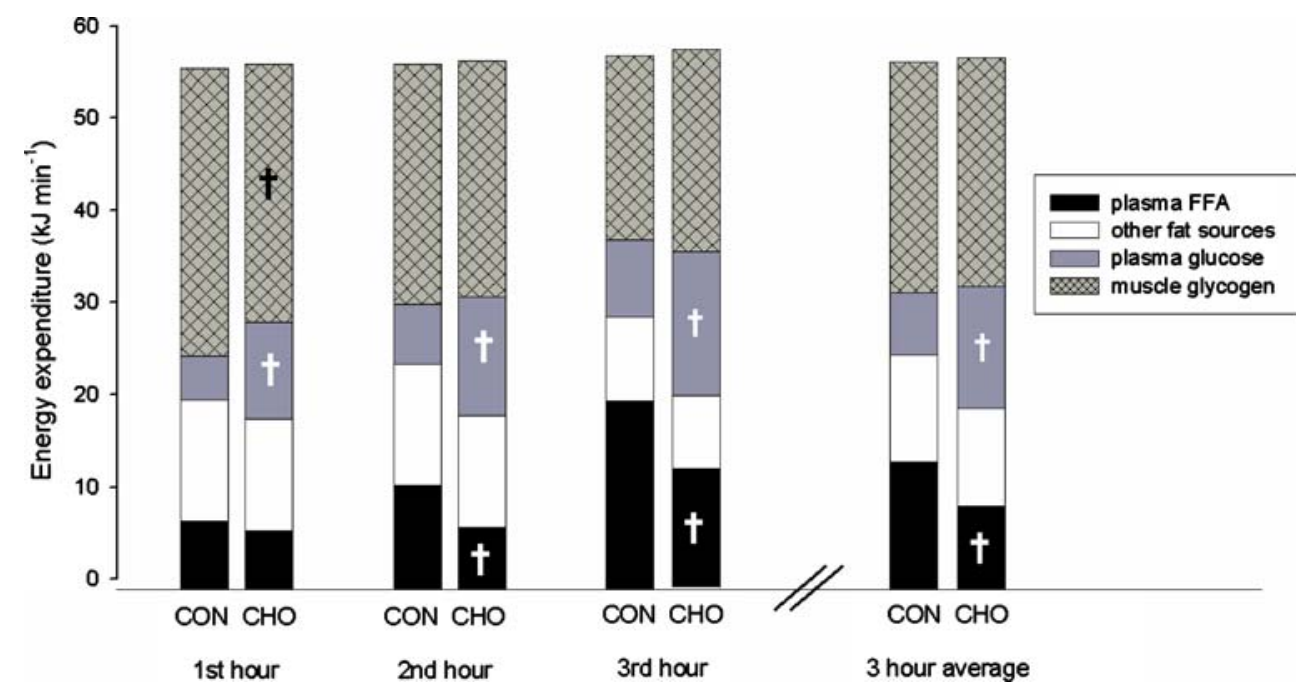




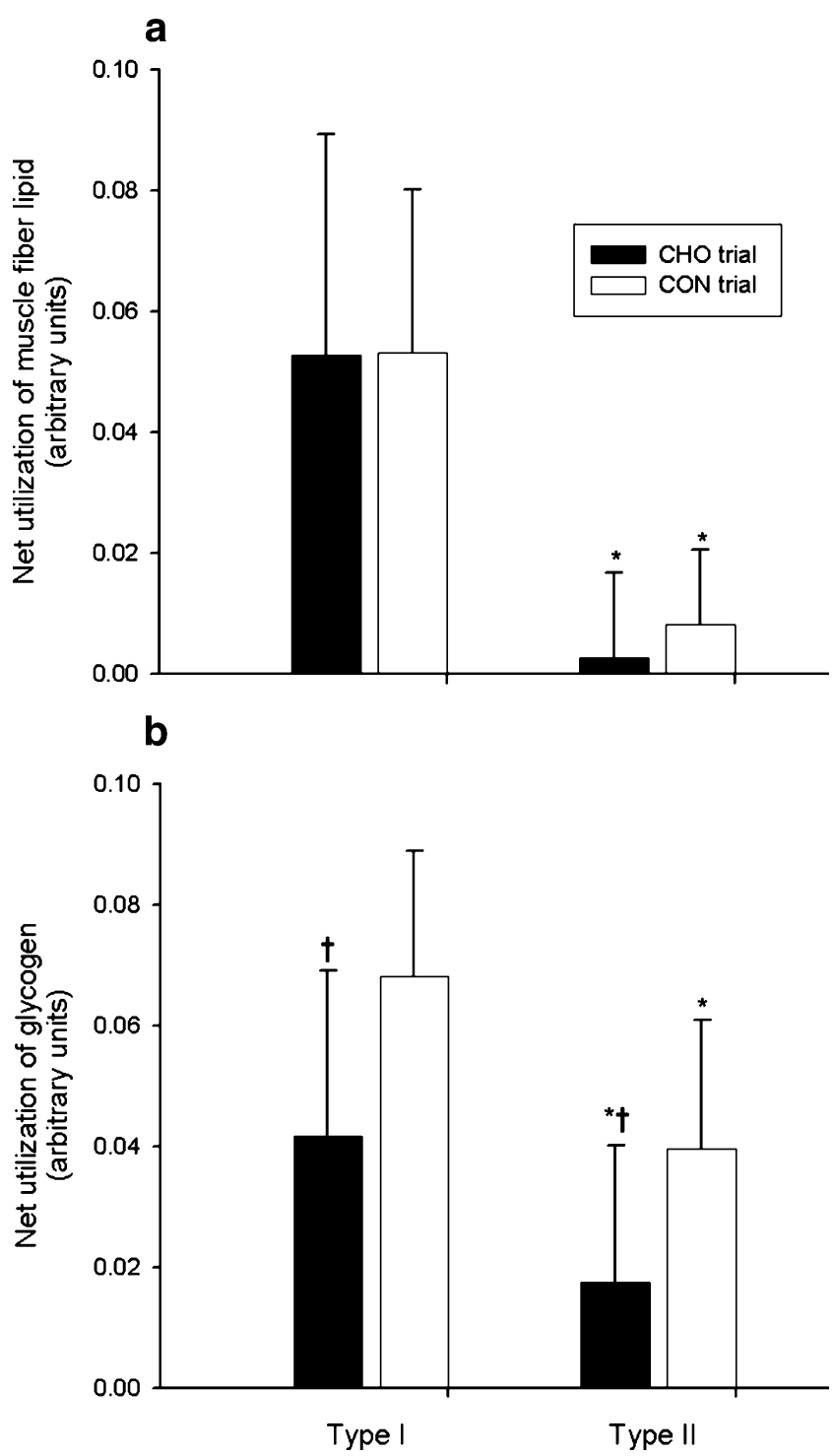

Fig. 6 Fiber-type-specific net intramyocellular lipid and glycogen utilization (expressed as mean arbitrary units $\pm \mathrm{SD}, n=10$ ) during $3 \mathrm{~h}$ of cycling at $50 \% W_{\max }$ in $\mathrm{CON}$ and $\mathrm{CHO}$ trials. Asterisk, type II significantly different than type I $(P<0.05)$; Crosses, significantly different from the CON trial $(P<0.05)$

density (preexercise, $0.119 \pm 0.031$; vs postexercise, $0.041 \pm$ 0.022 droplets $\mu \mathrm{m}^{-2}$ ).

Skeletal muscle glycogen content

At rest, glycogen contents did not differ between trials $(0.087 \pm 0.018$ vs $0.103 \pm 0.021 \mathrm{AU}$ in the $\mathrm{CHO}$ vs $\mathrm{CON}$ trial, respectively; $P>0.05)$ or between fiber types $(0.095 \pm$ 0.019 vs $0.094 \pm 0.021 \mathrm{AU}$ in the type I vs type II muscle fibers, respectively; $P>0.05)$. Exercise resulted in a significantly greater net reduction in muscle glycogen content in the type I vs the type II muscle fibers $(P<0.05$; Fig. 6b). The net decline in muscle glycogen content after exercise was significantly greater in the $\mathrm{CON}$ vs the $\mathrm{CHO}$ trial $(38 \pm 19$ and $57 \pm 22 \%$ greater in the type I and II muscle fibers, respectively; $P<0.01$ )

\section{Discussion}

The aim of this study was to examine substrate source utilization with $(\mathrm{CHO})$ or without $(\mathrm{CON})$ carbohydrate supplementation on subsequent glycogen and IMTG use during prolonged cycling exercise in endurance-trained male cyclists. Carbohydrate ingestion increased total carbohydrate oxidation, which was entirely attributed to a greater plasma glucose appearance $\left(R_{\mathrm{a}}\right)$ and disappearance $\left(R_{\mathrm{d}}\right)$ rate. The greater glucose availability in the CHO trial lowered muscle glycogen use during the first hour of exercise, resulting in significant muscle glycogen sparing in both type I and II muscle fibers after $3 \mathrm{~h}$ of exercise. Carbohydrate ingestion inhibited adipose tissue lipolysis, resulting in lower plasma FFA $R_{\mathrm{a}}, R_{\mathrm{d}}$, and $R_{\mathrm{ox}}$. The lower total fat oxidation rate was entirely attributed to reduced plasma FFA oxidation, as muscle IMTG use was not affected by carbohydrate supplementation.

IMTG use during prolonged exercise

The importance of the IMTG pool as a substrate source during exercise has been disputed. Many of the inconsistencies in the literature regarding IMTG use seem to be explained by the methodological limitations associated with the biochemical mixed-muscle TG extraction analyses [46]. More recent studies using either stable isotope tracers, ${ }^{1} \mathrm{H}$-magnetic-resonance spectroscopy, electron microscopy, and/or immunofluorescence microscopy on ORO stained muscle cross-sections have now established that IMTG is indeed a viable substrate source during exercise in healthy humans [37]. In accordance, substantial net reductions in type I muscle-fiber lipid content as assessed by immunohistochemical oil red $\mathrm{O}$ staining of muscle cross-sections have been observed after both endurance and resistance type exercise [11, 20, 41, 44]. Furthermore, our laboratory has found a significant correlation between IMTG contents assessed by biochemical TG extraction analyses and immunofluorescence microscopy on ORO stained muscle cross-sections (unpublished observations). In the present study, we observed a significant $20 \pm 3$ and $19 \pm 2 \%$ contribution from muscle- and/or lipoprotein-derived TG sources use during exercise in the $\mathrm{CHO}$ and $\mathrm{CON}$ trial, respectively (Fig. 5). Concomitantly, muscle biopsy analyses revealed a $76 \pm 21$ and $78 \pm 22 \%$ net decline in type I muscle-fiber IMTG content in the $\mathrm{CHO}$ and $\mathrm{CON}$ trial, respectively (Fig. 6a). This translated in a $67 \pm 19$ and $70 \pm$ $20 \%$ decline in mixed-muscle intramycellular lipid content in the $\mathrm{CHO}$ and $\mathrm{CON}$ trial, respectively. 
IMTG utilization during prolonged exercise with carbohydrate supplementation

Earlier estimations [28] and more recent findings [41, 45] show that the progressive increase in plasma FFA delivery during the latter stages of prolonged exercise suppresses IMTG mobilization and/or oxidation. In agreement, pharmacological inhibition of adipose tissue lipolysis has been shown to reduce plasma FFA availability and augments IMTG use during exercise [42, 44, 47]. This possibly suggests that during situations of decreased FFA availability there is a compensatory increase in IMTG utilization in vivo in humans. Carbohydrate supplementation during exercise also inhibits adipose tissue lipolysis and reduces plasma FFA availability [9, 10]. Therefore, it could be speculated that carbohydrate supplementation could augment IMTG use during the latter stages of prolonged exercise. In the present study, carbohydrate supplementation resulted in a $23 \pm 17 \%$ reduction in whole-body fat oxidation because of the concerted reductions in adipose tissue lipolysis with a concomitant $41 \pm 12 \%$ lower plasma palmitate $R_{\mathrm{a}}, R_{\mathrm{d}}$, and $R_{\mathrm{ox}}$ when compared with the CON trial. Despite the attenuated increase in plasma FFA availability in the $\mathrm{CHO}$ trial, no differences in estimated IMTG use were observed between trials (Figs. $4 \mathrm{~b}$ and 5). In agreement, after exercise, type I muscle-fiber lipid content was similarly reduced by $76 \pm 21$ and $78 \pm 22 \%$ in the $\mathrm{CHO}$ and $\mathrm{CON}$ trial, respectively (Fig. 6a).

In the present study, we did not observe any differences in IMTG use after carbohydrate ingestion. This might be because of the metabolic effects of increased glucose availability in the $\mathrm{CHO}$ trial, as we observed a $49 \pm 9 \%$ greater glucose $R_{\mathrm{a}}$ (Table 2) and a subsequent $48 \pm 9 \%$ higher plasma glucose oxidation rate throughout exercise (Fig. 4c). Furthermore, carbohydrate ingestion elevated plasma insulin concentrations by nearly $60 \%$ in the first hour of exercise vs CON (Fig. 2f). Elevated plasma insulin is a potent inhibitor of adipose tissue lipolysis [6], resulting in a substantially lower FFA availability in the $\mathrm{CHO}$ vs CON trial (Table 2). Although reduced plasma FFA availability could stimulate IMTG hydrolysis by reducing the allosteric inhibition of hormone-sensitive lipase (HSL) [44], we did not observe greater IMTG use in the CHO trial (Figs. $4 \mathrm{~b}$ and $6 \mathrm{a}$ ). However, this elevated plasma insulin could also serve to inhibit HSL activity, as a recent study showed blunted HSL activity during exercise when glucose is ingested [48]. Watt et al. [48] suggested that the decreased HSLa was most likely mediated via increased insulin and decreased epinephrine concentrations, and that even in situations when local intramuscular mediators of HSL are altered (i.e., muscle contraction, substrates/ products), the concurrent hormonal milieu may play a greater role in the activation of HSL. This previous study also found no effect of glucose ingestion on estimated IMTG oxidation, despite a decrease in plasma FFA availability and HSL activity [48].

Our present findings are not in line with de Bock et al. [11], who reported attenuated IMTG use after carbohydrate supplementation during a more intense exercise session in less-well-trained subjects. As such, we conclude that the proposed stimulating effects of reduced plasma FFA availability on IMTG mobilization and/or oxidation are offset by the inhibitory effects of carbohydrate supplementation on IMTG hydrolysis. The latter likely includes the greater glycolytic flux (Table 2), concomitantly higher circulating insulin (Fig. 2f), and decreased epinephrine levels (Fig. 3), all of which have been associated with reduced HSL activity in muscle tissue [48].

Effects of carbohydrate supplementation on muscle glycogen use

It has been established that prolonged moderate-intensity exercise results in greater glycogen depletion in type I vs type II muscle fibers $[8,14]$. In accordance, we observed a $73 \pm 25$ and $42 \pm 18 \%$ greater net utilization of type I vs type II muscle-fiber glycogen content in the $\mathrm{CHO}$ and $\mathrm{CON}$ trial, respectively (Fig. 6b). This is the first study to show glycogen sparing during prolonged cycling exercise in both type I and II muscle fibers (Fig. 6b). This finding seems to be in contrast to most previous studies that failed to observed muscle glycogen sparing after carbohydrate supplementation during cycling exercise $[5,9,13,17,24$, 25]. In line with our findings, some studies have also reported muscle glycogen sparing after carbohydrate supplementation during running exercise [34, 35]. However, these studies reported muscle glycogen sparing to be restricted to the type I muscle fibers only $[34,35]$. The apparent discrepancy with our findings is likely explained by the differences in the type (running vs cycling) and duration (1-2 vs $3 \mathrm{~h}$ ) of the exercise that was implemented, as with increasing exercise duration, muscle-fiber-type recruitment shifts to include more type II fiber activation as the type I fibers become glycogen depleted [15].

Our findings of muscle glycogen sparing with carbohydrate supplementation during prolonged constant intensity cycling are in line with some $[4,12]$, but definitely not with the majority of studies $[5,9,13,17,24,25]$. The apparent discrepancy between the current study and prior work that failed to observe muscle glycogen sparing with carbohydrate supplementation during cycling might be explained by differences in training status of the subjects, the intensity and duration of the exercise, the amount and timing of the ingested carbohydrate, the absence of the time-dependent assessment of muscle glycogen use, and the lack of musclefiber-type-specific glycogen analyses. 
Glycogen sparing occurs early in exercise with carbohydrate supplementation

In agreement with our findings of skeletal muscle glycogen sparing, whole-body muscle glycogen use was lower during the initial hour of exercise in the $\mathrm{CHO}$ vs the CON trial (Fig. 5). In accordance to the hypothesis set forth by Coggan and Coyle [7], we observed a greater dependence on muscle glycogen as a substrate source during the early stages of exercise in the CON trial (Fig. 5). As exercise duration lengthened, the contribution of muscle glycogen decreased over time as muscle glycogen stores became depleted, while blood glucose uptake and oxidation rates increased progressively (Fig. 4). In line with this hypothesis, we observed lower muscle glycogen use during the initial hour of exercise in the CHO trial. At the onset of exercise, carbohydrate administration caused a $49 \pm 9 \%$ greater plasma glucose $R_{\mathrm{a}}$ and $R_{\mathrm{d}}$ in the CHO compared with the CON trial (Table 2), which paralleled a $60 \%$ increase in plasma insulin concentrations as compared to $\mathrm{CON}$ during the first hour of exercise (Fig. 2). Concomitantly, these changes because of the augmented glucose availability at exercise onset decreased the reliance of muscle glycogen as a fuel source during the first hour of exercise. The latter is in accordance with a previous work reporting significant glycogen sparing after carbohydrate supplementation after $60 \mathrm{~min}$ of running exercise [34]. We conclude that the majority of glycogen sparing because of carbohydrate supplementation occurs during the initial stages $(<1 \mathrm{~h})$ of prolonged exercise, resulting in lowered glycogen utilization in type I and II muscle fibers. As our findings show that muscle glycogen sparing after carbohydrate supplementation occurs early in exercise, endurance athletes should be recommended to initiate sports-drink consumption immediately at the onset of exercise to maximize the potential for glycogen sparing, along with maintaining euglycemia and high blood glucose oxidation rates late in exercise.

\section{Conclusions}

This study provides compelling evidence that carbohydrate supplementation spares muscle glycogen utilization in a time-dependent manner during prolonged exercise in endurance-trained cyclists. Carbohydrate supplementation augments plasma glucose uptake and oxidation rate, while reducing muscle glycogen use during the early stages of exercise, thereby sparing type I and II muscle fiber glycogen stores. Carbohydrate supplementation during exercise lowers plasma FFA rate of appearance, uptake, and oxidation, but does not modulate the use of IMTG as a substrate source during cycling exercise.
Acknowledgments This study was supported by a grant from the Dutch Sugar Foundation. We thank Rene Koopman, Richard A. Jonkers, Joan M. Senden, and Ralph J. Manders for much appreciated technical assistance, and all subjects for their enthusiastic support. Trent Stellingwerff was supported by an individual postdoctorate fellowship from the Natural Science and Engineering Research Council of Canada (NSERC).

\section{References}

1. American College of Sports Medicine, American Dietetic Association, and Dietitians of Canada (2000) Joint Position Statement: nutrition and athletic performance. American College of Sports Medicine, American Dietetic Association, and Dietitians of Canada. Med Sci Sports Exerc 32:2130-2145

2. Alberti KG, Zimmet PZ (1998) Definition, diagnosis and classification of diabetes mellitus and its complications. Part 1: diagnosis and classification of diabetes mellitus provisional report of a WHO consultation. Diabet Med 15:539-553

3. Bergstrom J (1975) Percutaneous needle biopsy of skeletal muscle in physiological and clinical research. Scand J Clin Lab Invest 35:609-616

4. Bjorkman O, Sahlin K, Hagenfeldt L, Wahren J (1984) Influence of glucose and fructose ingestion on the capacity for long-term exercise in well-trained men. Clin Physiol 4:483-494

5. Bosch AN, Dennis SC, Noakes TD (1994) Influence of carbohydrate ingestion on fuel substrate turnover and oxidation during prolonged exercise. J Appl Physiol 76:2364-2372

6. Campbell PJ, Carlson MG, Hill JO, Nurjhan N (1992) Regulation of free fatty acid metabolism by insulin in humans: role of lipolysis and reesterification. Am J Physiol 263:E1063-E1069

7. Coggan AR, Coyle EF (1991) Carbohydrate ingestion during prolonged exercise: effects on metabolism and performance. Exerc Sport Sci Rev 19:1-40

8. Costill DL, Gollnick PD, Jansson ED, Saltin B, Stein EM (1973) Glycogen depletion pattern in human muscle fibres during distance running. Acta Physiol Scand 89:374-383

9. Coyle EF, Coggan AR, Hemmert MK, Ivy JL (1986) Muscle glycogen utilization during prolonged strenuous exercise when fed carbohydrate. J Appl Physiol 61:165-172

10. Coyle EF, Jeukendrup AE, Wagenmakers AJ, Saris WH (1997) Fatty acid oxidation is directly regulated by carbohydrate metabolism during exercise. Am J Physiol 273:E268-E275

11. De Bock K, Richter EA, Russell AP, Eijnde BO, Derave W, Ramaekers M, Koninckx E, Leger B, Verhaeghe J, Hespel P (2005) Exercise in the fasted state facilitates fibre type-specific intramyocellular lipid breakdown and stimulates glycogen resynthesis in humans. J Physiol 564:649-660

12. Erickson MA, Schwarzkopf RJ, McKenzie RD (1987) Effects of caffeine, fructose, and glucose ingestion on muscle glycogen utilization during exercise. Med Sci Sports Exerc 19:579-583

13. Flynn MG, Costill DL, Hawley JA, Fink WJ, Neufer PD, Fielding RA, Sleeper MD (1987) Influence of selected carbohydrate drinks on cycling performance and glycogen use. Med Sci Sports Exerc 19:37-40

14. Gollnick PD, Armstrong RB, Saubert CWt, Sembrowich WL, Shepherd RE, Saltin B (1973) Glycogen depletion patterns in human skeletal muscle fibers during prolonged work. Pflugers Arch 344:1-12

15. Gollnick PD, Piehl K, Saltin B (1974) Selective glycogen depletion pattern in human muscle fibres after exercise of varying intensity and at varying pedalling rates. J Physiol 241:45-57

16. Gutmann I, Wahlefeld AW (1974) L-(+)-Lactate determination with lactate dehydrogenase and NAD. In: Bergmeyer HU (ed) 
Methods in enzymatic analysis. Academic, New York, pp 14641468

17. Hargreaves M, Briggs CA (1988) Effect of carbohydrate ingestion on exercise metabolism. J Appl Physiol 65:1553-1555

18. Jeukendrup AE, Raben A, Gijsen A, Stegen JH, Brouns F, Saris WH, Wagenmakers AJ (1999) Glucose kinetics during prolonged exercise in highly trained human subjects: effect of glucose ingestion. J Physiol 515(Pt 2):579-589

19. Kiens B, Essen-Gustavsson B, Christensen NJ, Saltin B (1993) Skeletal muscle substrate utilization during submaximal exercise in man: effect of endurance training. J Physiol 469:459-478

20. Koopman R, Manders RJ, Jonkers RA, Hul GB, Kuipers H, van Loon LJ (2005) Intramyocellular lipid and glycogen content are reduced following resistance exercise in untrained healthy males. Eur J Appl Physiol:1-10

21. Koopman R, Schaart G, Hesselink MK (2001) Optimisation of oil red $\mathrm{O}$ staining permits combination with immunofluorescence and automated quantification of lipids. Histochem Cell Biol 116:6368

22. Mabuchi K, Sreter FA (1980) Actomyosin ATPase. II. Fiber typing by histochemical ATPase reaction. Muscle Nerve 3:233239

23. Matthews DR, Hosker JP, Rudenski AS, Naylor BA, Treacher DF, Turner RC (1985) Homeostasis model assessment: insulin resistance and beta-cell function from fasting plasma glucose and insulin concentrations in man. Diabetologia 28:412-419

24. McConell G, Snow RJ, Proietto J, Hargreaves M (1999) Muscle metabolism during prolonged exercise in humans: influence of carbohydrate availability. J Appl Physiol 87:1083-1086

25. Mitchell JB, Costill DL, Houmard JA, Fink WJ, Pascoe DD, Pearson DR (1989) Influence of carbohydrate dosage on exercise performance and glycogen metabolism. J Appl Physiol 67:1843-1849

26. Peronnet F, Massicotte D (1991) Table of nonprotein respiratory quotient: an update. Can J Sport Sci 16:23-29

27. Pickert A, Overkamp D, Renn W, Liebich H, Eggstein M (1991) Selected ion monitoring gas chromatography/mass spectrometry using uniformly labelled (13C)glucose for determination of glucose turnover in man. Biol Mass Spectrom 20:203-209

28. Romijn JA, Coyle EF, Sidossis LS, Gastaldelli A, Horowitz JF, Endert E, Wolfe RR (1993) Regulation of endogenous fat and carbohydrate metabolism in relation to exercise intensity and duration. Am J Physiol 265:E380-E391

29. Schaart G, Hesselink RP, Keizer HA, van Kranenburg G, Drost MR, Hesselink MK (2004) A modified PAS stain combined with immunofluorescence for quantitative analyses of glycogen in muscle sections. Histochem Cell Biol 122:161-169

30. Sidossis LS, Coggan AR, Gastaldelli A, Wolfe RR (1995) A new correction factor for use in tracer estimations of plasma fatty acid oxidation. Am J Physiol 269:E649-E656

31. Siri WE (1956) The gross composition of the body. Adv Biol Med Phys 4:239-280

32. Steele R (1959) Influences of glucose loading and of injected insulin on hepatic glucose output. Ann N Y Acad Sci 82:420-430

33. Tsintzas K, Williams C (1998) Human muscle glycogen metabolism during exercise. Effect of carbohydrate supplementation. Sports Med 25:7-23

34. Tsintzas OK, Williams C, Boobis L, Greenhaff P (1995) Carbohydrate ingestion and glycogen utilization in different muscle fibre types in man. J Physiol 489(Pt 1):243-250
35. Tsintzas OK, Williams C, Boobis L, Greenhaff P (1996) Carbohydrate ingestion and single muscle fiber glycogen metabolism during prolonged running in men. J Appl Physiol 81:801809

36. Turcotte LP, Richter EA, Kiens B (1992) Increased plasma FFA uptake and oxidation during prolonged exercise in trained vs. untrained humans. Am J Physiol 262:E791-E799

37. van Loon LJ (2004) Use of intramuscular triacylglycerol as a substrate source during exercise in humans. J Appl Physiol 97:1170-1187

38. van Loon LJ, Greenhaff PL, Constantin-Teodosiu D, Saris WH, Wagenmakers AJ (2001) The effects of increasing exercise intensity on muscle fuel utilisation in humans. J Physiol 536:295-304

39. van Loon LJ, Koopman R, Manders R, van der Weegen W, van Kranenburg GP, Keizer HA (2004) Intramyocellular lipid content in type 2 diabetes patients compared with overweight sedentary men and highly trained endurance athletes. Am J Physiol Endocrinol Metab 287:E558-E565

40. van Loon LJ, Koopman R, Schrauwen P, Stegen J, Wagenmakers AJ (2003) The use of the [1,2-13C] acetate recovery factor in metabolic research. Eur J Appl Physiol 89:377-383

41. van Loon LJ, Koopman R, Stegen JH, Wagenmakers AJ, Keizer HA, Saris WH (2003) Intramyocellular lipids form an important substrate source during moderate intensity exercise in endurancetrained males in a fasted state. J Physiol 553:611-625

42. van Loon LJ, Manders RJ, Koopman R, Kaastra B, Stegen JH, Gijsen AP, Saris WH, Keizer HA (2005) Inhibition of adipose tissue lipolysis increases intramuscular lipid use in type 2 diabetic patients. Diabetologia 48:2097-2107

43. van Loon LJ, Schrauwen-Hinderling VB, Koopman R, Wagenmakers AJ, Hesselink MK, Schaart G, Kooi ME, Saris WH (2003) Influence of prolonged endurance cycling and recovery diet on intramuscular triglyceride content in trained males. Am J Physiol Endocrinol Metab 285:E804-E811

44. van Loon LJ, Thomason-Hughes M, Constantin-Teodosiu D, Koopman R, Greenhaff PL, Hardie DG, Keizer HA, Saris WH, Wagenmakers AJ (2005) Inhibition of adipose tissue lipolysis increases intramuscular lipid and glycogen use in vivo in humans. Am J Physiol Endocrinol Metab 289:E482-E493

45. Watt MJ, Heigenhauser GJ, Dyck DJ, Spriet LL (2002) Intramuscular triacylglycerol, glycogen and acetyl group metabolism during $4 \mathrm{~h}$ of moderate exercise in man. J Physiol 541:969-978

46. Watt MJ, Heigenhauser GJ, Spriet LL (2002) Intramuscular triacylglycerol utilization in human skeletal muscle during exercise: is there a controversy? J Appl Physiol 93:1185-1195

47. Watt MJ, Holmes AG, Steinberg GR, Mesa JL, Kemp BE, Febbraio MA (2004) Reduced plasma FFA availability increases net triacylglycerol degradation, but not GPAT or HSL activity, in human skeletal muscle. Am J Physiol Endocrinol Metab 287: E120-E127

48. Watt MJ, Krustrup P, Secher NH, Saltin B, Pedersen BK, Febbraio MA (2004) Glucose ingestion blunts hormone-sensitive lipase activity in contracting human skeletal muscle. Am J Physiol Endocrinol Metab 286:E144-E150

49. Wolfe RR, Jahoor F (1990) Recovery of labeled CO2 during the infusion of C-1- vs C-2-labeled acetate: implications for tracer studies of substrate oxidation. Am J Clin Nutr 51:248-252 